\title{
TENTH INTERNATIONAL CONGRESS OF ENTOMOLOGY
}

$\mathrm{T}$ HE Tenth International Congress of Entomology, which took place in Montreal, Canada, during August 17-25, 1956, was perhaps the largest gathering of entomologists ever held. More than fourteen hundred members attended, of whom 1,140 were from North America and 280 from overseas; among the latter, the British group was the largest (65), followed by France, West Germany, the Netherlands and Japan. The Soviet Union sent seven delegates, and Poland, Bulgaria, Romania and East Germany were represented. With the exception of China and of parts of South America and the Near East, the Congress attracted a world-wide membership.

Both McGill University and the University of Montreal provided accommodation. The Congress was generously supported by the Government of Canada, by the Province of Quebec, several other provinces and the City of Montreal, and also by the United Nations Educational, Scientific and Cultural Organization, the Canadian Pulp and Paper Association, and many other commercial and learned organizations. It thus became possible to offer considerable financial assistance to many overseas entomologists. A gratifying result of this was that one hundred and fifty members took part in the post-congress tours and about seventy others visited laboratories independently, giving visiting scientists the opportunity to see something of the remarkable increase in entomological effort in Canada since the War.

The Congress, under the presidency of Dr. W. R. Thompson, comprised fifteen sections with some seven hundred and twenty papers and many exhibits and films. Comment on this wealth of material must be restricted to relatively fow items.

The one general session was introduced by a recorded address from Dr. Karl Jordan, the founder (in 1910) and honorary life president of these congresses. Dr. Jordan, now ninety-five, had attended all previous meetings. Then followed the presidential address on "The Interpretation of Taxonomy" and papers by Dr. Pierre Maillet (France) on Phylloxera and by Prof. O. W. Richards (Great Britain) on "The Science of Ecology".

A group of sessions on systematics was devoted to individual orders of insects. At a symposium on the attributes, variation and taxonomy of the species, E. O. Wilson (United States) discussed the tendency of related species to differ more markedly where they become sympatric; W. J. Brown (Canada) described his work on sibling species in the Chrysomelidae; W. L. Brown (United States) considered successive expansion and contraction of range and its effects on gene flow and speciation ; and R. I. Usinger (United States) discussed the ecology of closely related sympatric species in the light of Gause's and Nicholson's studies of competition.

The section on genetics, cytology and biometrics included a symposium on the genetics of insect populations, with contributions from C. L. Remington (United States) on Lepidoptera, G. Stehr (Canada) on sex-limited dimorphism, J. C. King (United States) on DDT-resistant strains of Drosophila melanogaster, and Elisabeth Goldschmidt (Israel) on natural populations of Drosophila subobscura. A strong group of cytological papers included contributions by $\mathrm{T}$. Yosida (Japan) on autosome-sex chromosome relationships, Ann Sanderson (Great Britain) on Ptinus latro, and Sally Hughes-Schrader (United States) on the deoxyribonucleic acid content of the nucleus. The applications of cytology and genetics to taxonomy received special attention from G. K. Manna (India), D. Leston (Great Britain), G. Cousin (France), and several Canadian workers. There was a lively biometrics section, with considerable discussion following the papers.

In the section devoted to geographical distribution, papers analysing the composition of regional faunas were prominent. For example, J. L. Gressitt (Hawaii) showed that the fauna of New Guinea had an ancient south-east Asian origin, but was isolated more markedly than at present through most of the Tertiary and produced a high degree of endemism. W. Förster (Germany) showed that the Altiplano and high mountains of Bolivia have strong holaretic affinities, while the lower lying areas have a neotropical fauna of complex origin. The most important group of papers, however, was the symposium on the distribution of arctic and sub-arctic insects, held jointly with the section on systematics. There was much discussion of the terms 'arctic' and 'sub-arctic', and some discrepancies in their usage. The dividing line is sharply correlated with the tree line in Canada, but not in Alaska or Europe. C. H. Lindroth (Sweden) demonstrated that the greatest barrier to dispersal in Pleistocene and recent times has been the Davis Strait. A series of papers on individual groups included a noteworthy account of arctic blackflies by G. E. Shewell (Canada); W. R. M. Mason (Canada) discussed distributional problems in Alaska, and A. B. Klots (United States) southward extensions of the arctic fauna. The symposium ended with papers on the origin of the arctic fauna by G. Warnecke (Germany) and E. G. Munroe (Canada). There were in all nineteen contributions, but unfortunately none relating to the great Siberian sector of the arctic.

In the section on morphology and anatomy the relationship of insects to other arthropods was discussed at length. G. F. Ferris and F. M. Butt (United States) and E. M. Du Porte (Canada) approached the question through analyses of the segmental constitution of the head. R. E. Snodgruss (United States) considered the structure of the tentorium and its antecedents in Crustacea and Myriapoda. S. L. Tuxen (Denmark) assembled the evidence concerning the position of the Protura; he concluded that they should be regarded as true insects, most closely related to the Diplura. E. Handschin (Switzerland) did the same for the Collembola but arrived at rather differont conclusions - that the Collombola, Protura and Diplura are more closely related to the Myriapoda than to the Insecta.

Among other interesting contributions, G. Richard (France) described the growth of Johnston's organ in termites and phasmids and traced the changes that occur during the moult. C. Noirot (France) showed that rudiments of the gonoduct of the opposite sex exist in young nymphal termites, confirming Hey. mons's (1895) work on embryos of cockroaches. S. Kramer (United States) showed that the wing muscles of Periplaneta americana are opaque and pink in the males but hyaline and white in the non. flying females, and related these differences to the metabolism and mechanism of flight. 
In the palæontology section, B. B. Rohdendorf (U.S.S.R.) outlined recent studies of the rich Carboniferous and Permian insect beds in southern Siberia; 262 species of 12 orders have been described, the Cupedidae and the Curculiopseidae (Coleoptera) being particularly abundant. Four faunas can be distinguished and compared.

Papers on the Arachnida were not numerous, but included interesting contributions on the phylogeny and taxonomy of the Acari. A. Shulov (Israel) described the production of spermatophores in scorpions, but the way they are transferred to the female remains uncertain; and G. W. Byers (United States) showed that in Trombicula also insemination is by an external spermatophore.

Physiology and toxicology, one of the strongest sections of the Congress, included sessions on neuromuscular systems and insecticidal activity, temperature effects, the sensory and nervous systems, nutrition, problems of metabolism, periodic phenomena and resistance to insecticides. The symposium on the nature, origin and activity of insect hormones attracted contributions from D. Bodenstein, Berta Scharrer and C. M. Williams (United States), V. B. Wigglesworth (Great Britain), L'. Karlson (Germany), B. Possompès (France), A. F. O'Farrell (Australia), D. M. Steinberg (U.S.S.R.) and M. Ichikawa (Japan).

H. A. Schneiderman (United States) showed that the spiracles of the Cecropia moth behave as independent effectors sensitive to carbon dioxide and oxygen, and rolease respiratory carbon dioxide in periodic bursts. B. N. Smallman (Canada) discussed the inhibition of cholinesterase by organo-phosphorus compounds, and A. G. Richards (United States) contributed a notable paper on the effect of temperature on organ- and enzyme-systems. E. Hecker (Germany) reported the isolation and identification of the sexattractant of the female silkworm and established a unit on behavioural criteria.

In the behaviour section, Ilse Schwinck (Germany) complemented Hecker's paper by her account of activation and orientation of male moths by the sex odours. V. G. Dethier (United States) described the rudimentary dance performed by blowflies after feeding, and suggested the existence of a general pattern of insect behaviour that bees have perfected as a means of communication. D. Magnus (Germany) showed a film illustrating his analysis of the mating of Argynnis, and J. A. Downes (Canada) discussed the mating of Nematocera and the correlated modifications in the behaviour, ecology and sensory equipment of aberrant species. J. S. Kennedy (Great Britain) described observations on aphids that lend support to an emended chain-reflex theory of instinct.

'The sessions on social insects were sponsored jointly with the International Union for the Study of Social Insects and included some twenty papers. C. D. Michener (United States) considered that social behaviour in bees originated from interrelations among the adult insects, contrary to Wheeler's theory. J. S. Moure (Brazil) showed that colony multiplication in the Meliponini involves transport of materials from the mother colony before and after the flight of the young queen. T. Eisner, W. L. Brown and E. O. Wilson (United States) discussed food-sharing and the evolution of ants, paying special attention to the functions of the proventriculus. A. E. 'Treat (United States) gave a fascinating account of the sub-social mite Myrmonyssus, which colonizes one only of the paired tympanic organs of moths. In a session devoted to nest structures, the paper by P. P. Grassé and C. Noirot (France) on termites was especially noteworthy.

An important group of papers distributed between ecology and forest entomology were concerned with the fundamental causes of numerical variation of populations in Nature. A. D. Voutte (Netherlands) and G. C. Varley (Great Britain) argued in a general way for the view that populations are regulated by factors the destructive intensity of which varies with population density, increasing as the density rises, decreasing as it falls; A. Milne (Great Britain) held that the numerical variations are due to chance, and the fact that numbers may be maintained at a reasonable constancy by random factors was shown in an interesting statistical experiment by $\mathbf{F}$. Schwerdtfeger (Germany); L. C. Cole (United States), in a paper which aroused great interest, showed that series of numbers selected at random have often a distinetly eyclical character, suggesting the existence of rhythmically acting natural factors which do not in fact exist; and that there may also be numerical correlations completely devoid of factual significance.

The forest entomology programme also included sessions on insect surveys, chemical control, and forest management problems. Other papers discussed the problems of particular areas and reported studies of the ecology, natural and chemical control, and hazard appraisal of forest insects in many parts of the world.

Appropriately, several papers concerned the spruce budworm, the insect of perhaps the greatest significance in the Canadian economy. R. F. Morris analysed life-tables and discussed population dynamics; the very large-scale aerial spraying operations in the Maritime Provinces and in Oregon were considered by F. E. Webb and J. M. Whiteside, respectively; and the point of view of industrial management on cultural control was ably presented by B. W. Elieger.

The well-attended sessions on biological control, with ninety-one papers from twenty-four countries, were a remarkable indication of current interest. A series of papers was devoted to reviews covering the broad field over much of the world. Two long symposia on orchard mites and their natural control and on the biological control of the balsam woolly aphid included specialist contributions from many parts of Europe and North America. A session on insect pathology and another on the utilization of microorganisms also brought to light much interesting information and showed how fungi, bacteria and viruses, as well as nematodes, have become more conspicuous among the beneficial organisms used. Other subjects treated at length included the control of weeds, the role of ants in biological control and adaptation by parasitic insects.

The section of agricultural entomology, the largest. in the Congress, devoted seven meetings to special topics. The tension between the method of chemical control on one harıd and the ocological approach and the need for conserving valuable natural enemies on the other was prominent in the sessions on locusts and grasshoppers, on contrasting approaches to orchard entomology, and on soil insects, all of which drew many distinguished contributions. B. A. Porter (United States) reviewed recent work on the fruit fly problem in temperate regions, and L. D. Christenson (United States) showed that attractants, especially protein hydrolysate and poisoned methyl 
eugenol, are proving valuable in the tropics. There was an important session on insect transmission of viruses, with the papers equally divided between entomologists and plant pathologists, and a detailed examination of the international and legal problems arising from insecticide residues. Advisory entomology, the United States technical assistance programmes, recent advances in insecticide application and the problems of special crops were also considered.

In the relatively small section on stored products entomology, the international problems arising from the variation in storage facilities and from the movement of insect-infested produce were examined by S. S. Easter (United States) and J. A. Froeman (Great, Britain). Contributions by R. W. Howe (Great Britain) on the potential range and importance of the Khapra beetle, and by H. M. Armitage (United States) on methods of eradication, proved to be of such general interest that an additional session was organized. Other papers described new methods of detecting hidden infestation in grain, new fumigation tech niques, and problems of storage in warm climates.

In the section on medical and veterinary entomology, symposia were held on the entomology of filarial infections, on animal viruses in arthropods, and on the biology and control of blackflies. In the first two the speakers concentrated on the arthropod vectors, what happens in them when infected, their biology and how this affects epidemiology. The blackfly papers reported advances made in Africa, Central America, the United States, Canada and Great Britain. Malaria and its vectors were discussed in papers from the World Health Organization and from India, Africa, Vietnam, Timor and elsewhere. Other papers on vectors and disease dealt with mites and scrub typhus in Malaya, ticks and tick paralysis in Canada, and problems resulting from the development of water resources in the United States. There were small groups of papers on the biology of cattle warbles and their control with systemic insecticides, on Phlebotomus, and on techniques for artificial feeding of blood-sucking arthropods. Other contributions of note concerned the periodicity of bitingfly attack in the U.S.S.R. and in Africa, and the transmission of blood parasites of ducks by Culicoides and of snakes by the mite Ophionyssus.

The discussions on apiculture ranged over nectar secretion, the composition of honey, and the behaviour, physiology and diseases of bees. A series of papers considered the pollination of fruit and logume erops by Apis and wild bees. R. Chauvin (France) reported that intra-muscular injection of royal jelly in man induced neutropenia and reticulocytosis, accompanied by a pronounced euphoria. Some $200 \mathrm{kgm}$. of royal jelly is harvested annually in France for therapeutic use.

I am greatly indebted to the leaders of the sections for assistance in compiling the foregoing account.

At the closing session of the Congress, Prof. A. da Costa Lima, of Brazil, and Dr. J. Chester Bradley, of the United States, were elected honorary members. Mr. N. D. Riley resigned as secretary of the Permanent Committee, and Dr. D. J. Kuenen, of the Netherlands, was elected in his place. It was decided to hold the eleventh congress in Vienna in 1960.

The Proceedings of the Congress, which will include most of the papers presented, will be published shortly. Inquiries should be addressed to J. A. Downes at the Science Service Building, Ottawa, Canada.

\section{CAMBRIDGE OBSERVATORIES}

\author{
REPORT FOR 1955
}

$T$ HE report of the Observatories Syndicate of the University of Cambridge for the year ending September 30, 1955*, deals first with solar research, and under this heading reference is made to Dr. H. von Klüber's work in completing and discussing the interferometric photographs of the green coronal line 5303 A., made in co-operation with Dr. A. H. Jarrett, of the University of St. Andrews Observatory, at the total eclipse of June 30, 1954. From measurements made in the range $1 \cdot 05-1 \cdot 3$ solar radii, and interpreting the line widths as due entirely to thermal motions, temperatures of the corona were found around $2.2 \times 10^{6}$ to $5 \times 10^{6}{ }^{\circ} \mathrm{K}$., most of the values being near $2 \times 5 \times 10^{\circ}{ }^{\circ} \mathrm{K}$. The results were so encouraging that preparations were made to observe the June 20 , 1955, eclipse at Hingurakgoda, using more extensive equipment; but unfortunately clouds prevented any results of scientific value being obtained by any of the eclipse expeditions to Ceylon. Dr. D. E. Blackwell has completed measurement and reduction of the corona photographs obtained by him at the 1954 eclipse, and a first paper was ready for publication when the report was compiled.

Dr. von Klüber has discovered that the large Mount Wilson diffraction grating, which gives a measured resolving-power of about 600,000 in the fifth order, allows remarkably clear visual observations of a fine structure of Fraunhofer lines, consisting of shifts and distortions arising from the solar granulation. The effects are seen in varying degrees in nearly all lines of the solar spectrum, but are most conspicuous in the hydrogen lines. Examination of the fine structure, using an electro-optical shutter of the A.D.P. type, failed to detect any local magnetic fields, but Dr. von Klüber and Dr. B. E. J. Pagel have started further work on this question. Various other matters are referred to in the report under solar research, among which may be noticed the balloon project mentioned in earlier reports. Dr. D. W. Dewhirst and Dr. Blackwell, by arrangements made through the Royal Society for co-operation with the Royal Air Force, made four flights in 8 Lincoln aircraft, and photographed the Sun, through an open door, with a 7 -in. refractor. Owing to vibration, but still more to air disturbance set up by the machine, it does not appear that high-resolution photographs of the Sun are likely to be obtained from conventional aircraft.

In the section dealing with the 17-in. Schmidt telescope, reference is made to the work of Dr. Dewhirst, assisted by G. G. Yates and A. N. Argue, in searching with the instrument for discrete radio sources. Using blue-sensitive plates going to a limiting magnitude about $18 \cdot 5$, a small number of faint galaxies have been detected the positions of which agree with radio sources of small diameter, but otherwise no peculiar stellar or extragalactic object has been found in the positions given. In addition, photographs in the blue, and with a plate filter combination for $\mathrm{H} \alpha$, have given no evidence to support the idea that either Hii regions or clusters of galaxies are responsible for the majority of sources of large diameter. Workers at the Cavendish Labora. tory have found a significant correlation between the

- University of Cambridge. Report of the Observatories Syndicate for the Year ending 1955, September 30 . (Cambridge: The University, 1956.) 